\title{
Compound Depressed Fracture Over Dural Venous Sinuses: Experience of 22 Surgically Treated Cases
}

\author{
KHALED ISMAIL ABDEL-AZIZ, M.D.* and MOHAMED ALI RAGAEE, M.D.** \\ The Department of Neurosurgery, Faculty of Medicine, Aswan* and Assuit** Universities Hospital
}

\begin{abstract}
Background: Due to high risk of massive blood loss of traumatic injury of dural venous sinus at the time of trauma or emergency operation leading to high mortality rate, we considered the appropriate methods that are most essential in treatment of depressed skull fracture over dural venous sinus to decrease mortality rate as much as possible.
\end{abstract}

Aim of Study: For assessment of surgical interference in cases of depressed skull bone fracture with dural venous sinuses injury is it risky with high mortality rate or can be done safely with different methods or it is better to be conserve than surgical interference.

Patients and Methods: Twenty two patients with transsinus compound depressed skull fracture were reviewed retrospectively who presented to emergency department in Aswan university hospitals between January 2014 and June 2018. All patients submitted to computed tomography scan (CT scan) for assessment of fracture site, size and relation to dural venous sinuses.

Results: Twenty two patients with a dural venous sinus injury from severe head injuries who had been treated upon in the two hospitals were reviewed retrospectively. There were 18 males and 4 females patients. All cases underwent surgical interference, with mortality rate $(22.73 \%)$ of operated cases, due to massive blood loss intraoperative and uncontrolled sinus repair and hypovolemic shock.

Conclusion: When there is depressed skull fracture penetrating the sinus, so we will take care for possibility of massive blood loss and uncontrolled repair of injured sinus, and we face a high mortality case. The surgeon should be prepared for the possibility of potentially fatal venous sinus injury, and so, conservative treatment better than surgical intervention of penetrating cases of dural venous sinus injuries as much as possible.

Key Words: Cranial sinus injury - Skull fractures.

\section{Introduction}

THE incidence of cranial sinus injury due to depressed skull bone fractures ranges up to 4 percent in civilian life in the respective literature $[\mathbf{1 , 2 , 3 ]}$

Correspondence to: Dr. Khaled Ismail Abdel-Aziz, E-Mail: khaledis2020@yahoo.com
The importance of dural sinus injury are due to the probability of massive blood loss at the time of trauma or emergency surgical interference which related to high mortality rate during the perioperative period [4].

The most commonly affected sinus is superior sagittal sinus (sss) about (70-80\%) among head trauma patients who are diagnosed with dural sinus injury [5]

Conservative treatment is recommended for simple depressed fracture to avoid risks of uncontrolled sinus bleeding or occlusion [6,7] .

So cases with major sinus injury, conservative treatment are advised unless there is active bleeding or development of idiopathic intracranial hypertension $(\mathrm{ICH})[8,9]$.

So, we performed a review for assessment of this cases of dural venous injuries about their clinical assessment, management and outcome of patients after surgical interference and follow-up (Table 1).

\section{Patients and Methods}

Retrospective review was conducted for patients with dural venous sinus injury between January 2014 and June 2018. We included all surgically treated cases among them. For each patient, clinical data (age, sex, glascow coma scale (GCS)), intraoperative control of bleeding, and postoperative complications, were recorded in Table (1). Glasgow Coma Scale (GCS) was used to assess the neurological status and follow up. Computed tomography (CT) scans head were taken in all cases as skull fracture and location of the injured sinus were recorded and the relation of the injured sinus, depressed and overlying sinus or depressed and penetrating sinus. 
Table (1): Summary of clinical data.

\begin{tabular}{|c|c|c|c|c|c|c|}
\hline No. & $\begin{array}{l}\text { Age/ } \\
\text { sex }\end{array}$ & $\begin{array}{c}\text { Pre-op } \\
\text { GCS }\end{array}$ & $\begin{array}{l}\text { Location } \\
\text { of injured } \\
\text { sinus }\end{array}$ & $\begin{array}{l}\text { Relation } \\
\text { of fx. } \\
\text { and sinus }\end{array}$ & $\begin{array}{l}\text { Bleeding } \\
\text { control }\end{array}$ & $\begin{array}{c}\text { GCS on } \\
\text { discharge }\end{array}$ \\
\hline 1 & $62 / \mathrm{M}$ & 15 & Ant $1 / 3$ sss & Overlying & Simple & 15 \\
\hline 2 & $24 / \mathrm{M}$ & 14 & Mid1/3sss & Penetrating & Failed & Expired \\
\hline 3 & 33/M & 15 & Mid1/3sss & Overlying & Difficult & 13 \\
\hline 4 & $18 / \mathrm{M}$ & 7 & TS & Overlying & Simple & 15 \\
\hline 5 & $27 / \mathrm{M}$ & 4 & Ant $1 / 3$ sss & Overlying & Simple & 15 \\
\hline 6 & $6 / \mathrm{M}$ & 9 & Ant $1 / 3$ sss & Overlying & Simple & 15 \\
\hline 7 & $34 / \mathrm{M}$ & 13 & Ant $1 / 3$ sss & Overlying & Simple & 15 \\
\hline 8 & $28 / \mathrm{M}$ & 8 & Ts & Overlying & Simple & 15 \\
\hline 9 & $51 / \mathrm{M}$ & 19 & Mid.1/3sss & Overlying & Simple & 15 \\
\hline 10 & $23 / \mathrm{M}$ & 7 & Ts & Overlying & Simple & 15 \\
\hline 11 & $41 / F$ & 14 & Ant.1/3 sss & Overlying & Simple & 15 \\
\hline 12 & $5 / F$ & 8 & Ts\&ss & Penetrating & Failed & Expired \\
\hline 13 & $34 / \mathrm{M}$ & 11 & Ant.1/3 sss & Penetrating & Difficult & 12 \\
\hline 14 & $25 / \mathrm{M}$ & 13 & Ant.1/3 sss & Penetrating & Difficult & 14 \\
\hline 15 & $9 / \mathrm{M}$ & 11 & Mid.1/3sss & Overlying & Simple & 15 \\
\hline 16 & $34 / \mathrm{M}$ & 4 & Mid.1/3sss & Overlying & Simple & 15 \\
\hline 17 & $49 / \mathrm{F}$ & 5 & Mid.1/3sss & Overlying & Simple & 15 \\
\hline 18 & $30 / \mathrm{M}$ & 10 & Post.1/3sss & Penetrating & Failed & Expired \\
\hline 19 & $58 / \mathrm{M}$ & 5 & Mid.1/3sss & Penetrating & Failed & Expired \\
\hline 20 & $37 / \mathrm{M}$ & 12 & TS\&SS & Penetrating & Failed & Expired \\
\hline 21 & $45 / \mathrm{M}$ & 13 & Ant.1/3 sss & Penetrating & Difficult & 15 \\
\hline 22 & $13 / \mathrm{F}$ & 15 & Ant.1/3 sss & Overlying & Simple & 15 \\
\hline $\begin{array}{l}\text { Pre- } \\
\text { GCS } \\
\text { SSS } \\
\text { TS } \\
\text { SS }\end{array}$ & \multicolumn{3}{|c|}{$\begin{array}{l}\text { : Preoperative. } \\
\text { : Glasgow Coma Scale. } \\
\text { : Superior sagittal sinus. } \\
\text { : Transverse sinus. } \\
\text { : Sigmoid sinus. }\end{array}$} & $\begin{array}{ll}\text { Fx } & : \text { Fr } \\
\text { Intraop }: \text { In } \\
\text { Ant }: \text { Ar } \\
\text { Mid }: \text { M } \\
\text { Post } & : \mathrm{Pc}\end{array}$ & $\begin{array}{l}\text { acture. } \\
\text { raoperative. } \\
\text { terior. } \\
\text { ddle. } \\
\text { sterior }\end{array}$ & \\
\hline
\end{tabular}

\section{Control of hemorrhage:}

"Simple" bleeding control means simple digital pressure using Gelfoam, temporal muscle or pericranium, or fascia. "Difficult" bleeding control was defined when the sinus bleeding could not be stopped by simple digital pressure and using more procedures to control the injured dural sinus as direct repair of injured sinus wall using simple suturing, hitching stitches from dura to the bone adjacent to the sinus.

Failure of all measures to control bleeding defined as "failed".

\section{Results}

From January 2014 and June 2018, 22 patients with a dural venous sinus injury with severe head injuries who had been managed in our clinic (Aswan university hospitals) were reviewed retrospectively (Table 1). The patients included 18 males and 4 females and their mean age at presentation was 31.9 years (range, 5 to 62 years).

The most common site of dural sinus injury was the superior sagittal sinus (SSS) occur in 17 cases. Other 5 cases, the transverse and sigmoid sinuses were injured. In 9 cases the anterior onethird of the SSS was injured, and 7 cases injured middle $1 / 3$ of SSS, the posterior one-third of the SSS injured in one case.

In 14 patients, a depressed skull fracture overlying the venous sinus was observed and in 8 cases the fracture penetrating the sinus based on CT findings.

In 14 patients with skull fracture overlying the dural venous sinus, massive bleeding from the injured sinus wall could be controlled by simple digital pressure using Gelfoam. The other procedures used is sutured of injured sinus and hitching stitches of adjacent dura to the adjacent bone, also ligation of rostral end of injured sinus were applied. During surgery 5 patients died due to hypovolemic shock, and the attempt to control hemorrhage from the injured sinus wall failed.

The neurological status at admission and discharge from the hospital were assessed using the GCS score.

The neurological symptoms and signs at discharge from the hospital improved in 17cases out of the 22 patients who underwent surgery, and 5 patients died.

\section{Illustrative cases:}

\section{Case 1:}

A 37-year-old man was hit in the head by iron of heavy metal and came immediately to our hospital. The patient with a GCS score of E3 V4 M5 on admission. CT scan head demonstrated a compound depressed skull fracture penetrating the left transverse sinus and sigmoid sinus (Fig. 1). There were ct scan head abnormality of brain including multiple hemorrhagic contusions, but no midline shift. Open reduction and wound irrigation were performed. During the operation, we encountered massive bleeding from large sized lacerated sinus after elevation of the bone fragments. Despite all efforts to control massive sinus bleeding, but his systolic blood pressure (BP) dropped and 4 units of blood were transfused. The patient expired due to hypovolemic shock during postoperative care. 

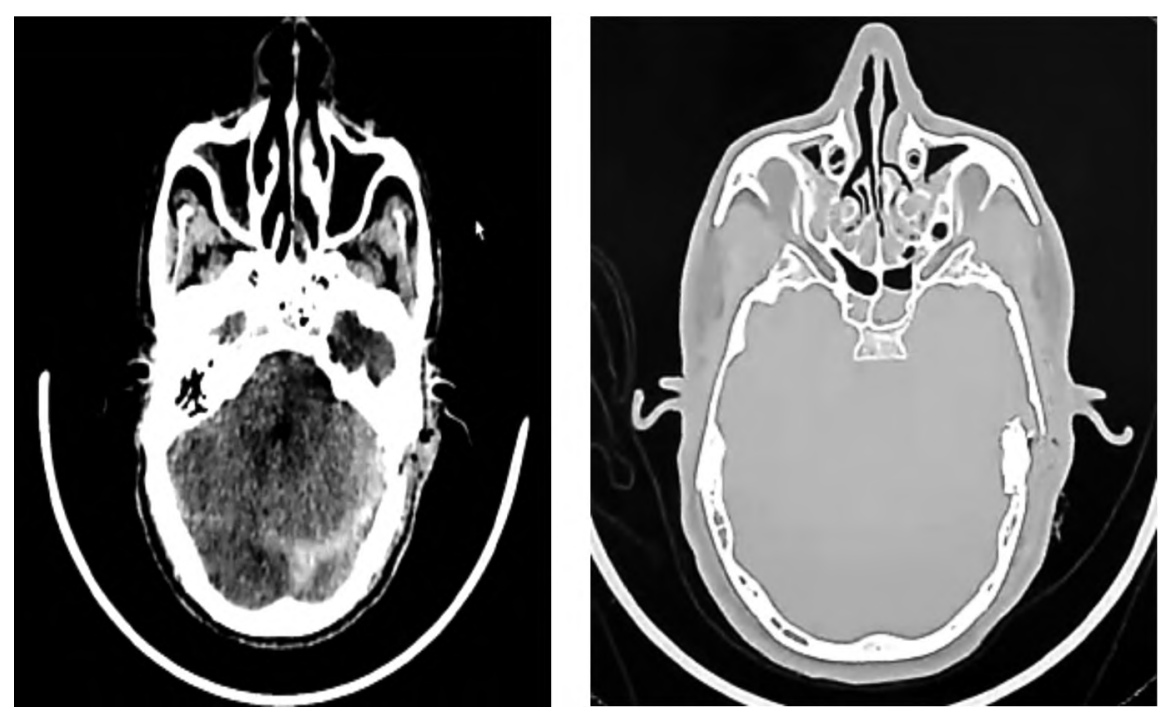

Fig. (1): Case one compound depressed fracture on TS/SS.M/37 years.

\section{Case 2:}

A 13-year-old female was brought to the emergency department after being struck in the head during a traffic accident. GCS score was E4 V5 M6 on admission. CT scan revealed an open compound depressed skull fracture overlying the anterior part of the superior sagittal sinus (Fig. 2). There was no other ct scan head abnormality. Emergency surgical intervention were performed. During operation, we encountered massive blood loss from the lacerated sinus wall due to the fracture. Bleeding was stopped by simple digital pressure using Gelfoam. The patient fully recovered and his GCS score was 15 at discharge.

\section{Case 3:}

A female patient 5 years old presented to our emergency deparment with GCS 8 with severe head injury and severe bleeding from right suboccpital region, CT head was done urgently after resuscitation of general condition, compound depressed fracture with penetrating transverse sinus and occipital sinus was revealed by CT scan head. Urgent surgical intervention was done, simple pressure over injured sinus failed and so, ligation of rostral end of injured sinus done to control of massive bleeding but it is failed and the patient died from massive blood loss.
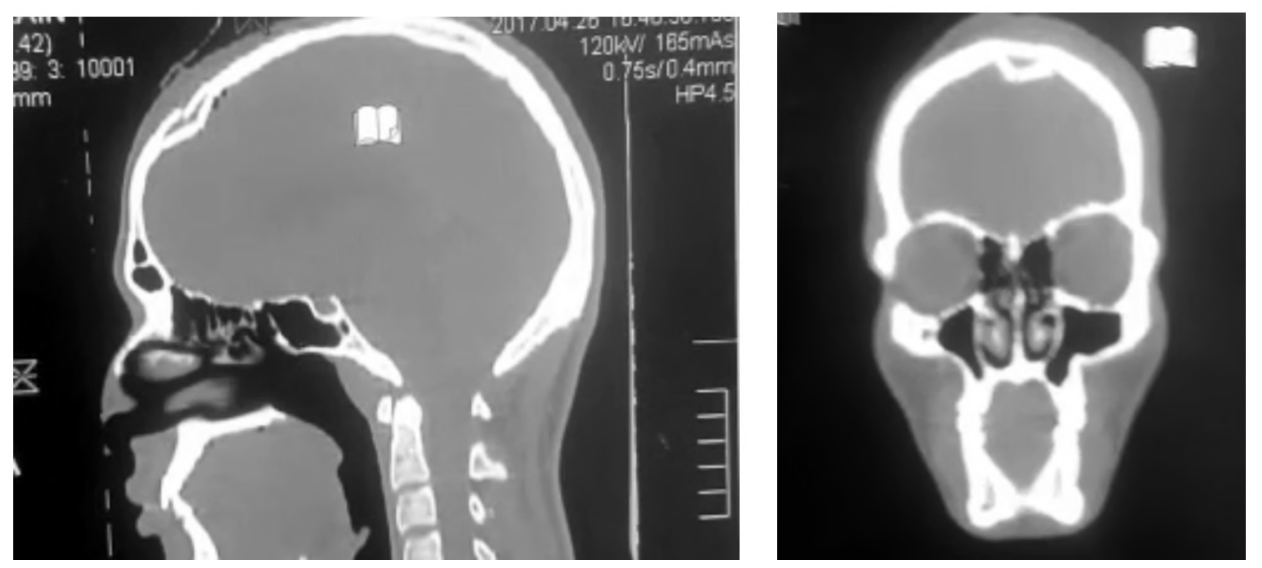

Fig. (2): $\mathrm{f} / 13$ years anterior $1 / 3$ of SSS.

\section{Discussion}

When dural sinus injury occurs, surgeons face high risk of massive blood loss intraoperative, Hence, the mortality rate associated with a sinus injury can increase to as high as $20 \%$ in the oper- ative period [1]. In our report, the incidence of mortality rate was $22.7 \%$.

The most common site of dural venous sinus injury is the anterior and middle one-third of the superior sagittal sinus. Meier et al., [4] Meirowsky, 
[10], Kapp and Gielchinsky [1] and Kapp et al., [2] reported that this same location has been noted in $66 \%, 57 \%, 74 \%$, and $82 \%$ of the patients respectively. In our study, 17 cases of the patients had an injury in the superior sagittal sinus from 22 cases $(77 \%)$, and other 5 patients with transverse sinus and sigmoid sinus (23\%).

Location of sinus injury is very important in the perioperative period for high risk of mortality and morbidity. Because there is more collateral venous drainage for tolerability of sinus injury or ligation, there is a decrease in mortality among patients with a sinus injury involving the anterior $1 / 3$ of the SSS.

Meier et al., [4] reported that $17 \%$ of the patients with sinus injury in the anterior one-third of the SSS result in death, whereas $50 \%$ of the cases with injury at the middle one-third and all patients with injury to the posterior part of SSS died.

In our study, 3 patients with sinus injury involving the SSS died ( 2 cases injured mid.1/3 \& one case injured post. 1/3 SSS) and 2 cases with injured to the transverse sinus and sigmoid sinus died.

Many operative procedures have been used to control massive blood loss from the injured sinus. Digital pressure with Gelfoam, temporal muscle or pericranium, or fascia is most frequently used simple method.

Another techniques, direct repair of injured sinus wall using simple suturing, hitching stitches from dura to the bone adjacent to the sinus, ligation of the the rostral part, occlusion of the rostral part by clips, transplantation of an autologous vein, artificial sinus prosthesis, balloon catheter, and Tdrainage have also been described [1,2] .

Also, tissue-glue-coated collagen sponge (TachoSil, Nycomed UK, Oxford, Buckinghamshire, UK) was a new recent report is also an effe-ctive surgical technique for repairing minor dural venous sinus laceration [11].

However, in our study, sinus bleeding could be stopped by mechanical pressure using gelfoam and also in difficult cases used suturing of injured sinus. In one case with severe bleeding which cannot stopped simply by direct pressure closure of injured sinus was done leading to venous infarction and patient was lost.

Meier et al., reported that mortality rates increased to as high as $23 \%$ to $60 \%$ in patients with brain stem lesion $[2,4]$
In our study, the overall mortality rate for 22 patients with dural sinus injury was $22.7 \%$ of operated cases.

LeFeuvre et al., [12] and Miller and Jennett [13] reported that the incidences of severe hemorrhagic complications in patients undergoing operative treatment for depressed skull fractures over a venous sinus are $23 \%$ and $20 \%$.

Miller and Jennett [13] also reported an incidence of $11.5 \%$ in cases with fracture penetration of a venous sinus. So, conservative management is strongly emphasized due to potential mortality resulting from uncontrollable bleeding. An open depressed skull fracture is usually repaired surgically and the dura is repaired as soon as possible to decrease the incidence of infection. However, in a closed depressed skull fracture, many authors recommend surgery only for 1 of the following 3 reasons: Evacuation of a hematoma, repair of obviously lacerated dura, or for correction of a severe cosmetic deformity [14].

In our study, most lost cases occurred from penetrating injured sinuses and better results from overlying sinuses.

It is thought that coagulopathy usually occurs due to massive transfusion after significant blood loss in patients with dural venous sinus injury. In a study by Behera et al., [5] thrombocytopenia occurred in $85 \%$ and defibrination occurred in $69 \%$ of cases with dural sinus injury.

Hence, coagulation profile investigation should be done during the perioperative period. Furthermore, preoperative angiography can also be useful to visualized venous sinuses before surgery [15]

But, in our cases angiographic evaluation was not performed because of unsuitable emergency situation.

\section{Conclusion:}

Many cases of massive bleeding from lacerated dural venous sinus could be controlled with simple digital pressure. But, when a depressed skull fracture penetrating the sinus, the surgeon should be prepared to face potential fatal venous sinus injury. So, it is better to be conserve as much as possible in cases of penetrating injured dural venous sinus than to be operated to avoid high mortality rate.

\section{References}

1- KAPP J.P. and GIELCHINSKY I.: Management of combat wounds of the dural venous sinuses. Surgery 71: 913 917, 1972 
2- KAPP J.P., GIELCHINSKY I. and DEARDOURFF S.L.: Operative techniques for management of lesions involving the dural venous sinuses. Surg. Neurol., 7: 339-342, 1977

3- RISH B.L.: The repair of dural venous sinus wounds by autogenous venorrhaphy. J. Neurosurg., 35: 392-395, 1971

4- MEIER U., GÄRTNER F., KNOPF W., KLÖTZER R. and WOLF O.: The traumatic dural sinus injury-a clinical study. Acta Neurochir (Wien) 119: 91-93, 1992

5- BEHERA S.K., SENAPATI S.B., MISHRA S.S., et al. Management of superior sagittal sinus injury encountered in traumatic head injury patients: Analysis of 15 cases. Asian. J. Neurosurg., 10: 17-20, 2015

6- DU PLESSIS J.J.: Depressed skull fracture involving the superior sagittal sinus as a cause of persistent raised intracranial pressure: A case report. J. Trauma 34: 2902, 1993.

7- UZAN M., CIPLAK N., DASHTI S.G., et al.: Depressed skull fracture overlying the superior sagittal sinus as a cause of benign intracranial hypertension. Case. Report. J. Neurosurg., 88: 598-600, 1998.

8- BIRK D.M., TOBIN M.K., MOSS H.E., et al.: Improvement in venous outflow following superior sagittal sinus decompression after a gunshot wound to the head: Case report. J. Neurosurg., 123: 81-5, 2015.

9- CAUDILL C.M., FRENCH L.A. and HAINES G.L.: Increased intracranial pressure following compression of the superior sagittal sinus. Neurology., 3: 231-3, 1953.

10- MEIROWSKY A.M.: Wounds of dural sinuses. J. Neurosurg., 10: 496-514, 1953.

11- GAZZERI R., GALARZA M., FIORE C., CALLOVINI G. and ALFIERI A.: Use of tissue-glue-coated collagen sponge (TachoSil) to repair minor cerebral dural venous sinus lacerations: Technical note. Neurosurgery, $11 \mathrm{Suppl}$, 2: 32-36, Discussion 36, 2015.

12-LEFEUVRE D., TAYLOR A. and PETER J.C.: Compound depressed skull fractures involving a venous sinus. Surg. Neurol., 62: 121-125, Discussion 125-126, 2004.

13- MILLER J.D. and JENNETT W.B.: Complications of depressed skull fracture. Lancet 2: 991-995, 1968

14- STEINBOK P., FLODMARK O., MARTENS D., GERMANN E.T.: Management of simple depressed skull fractures in children. J. Neurosurg., 66: 506-510, 1989.

15-OZER F.D., YURT A., SUCU H.K., TEKTAS S.: Depressed fractures over cranial venous sinus. J. Emerg. Med., 29: 137-139, 2005.

\section{كسر منخسف مضاعف بعظام الجمجمة فوق وقئ أوردة المبخ السحائية: تجرية علاج أثنين وعشرون حالة جراحيا أودة الهيخ اليا}

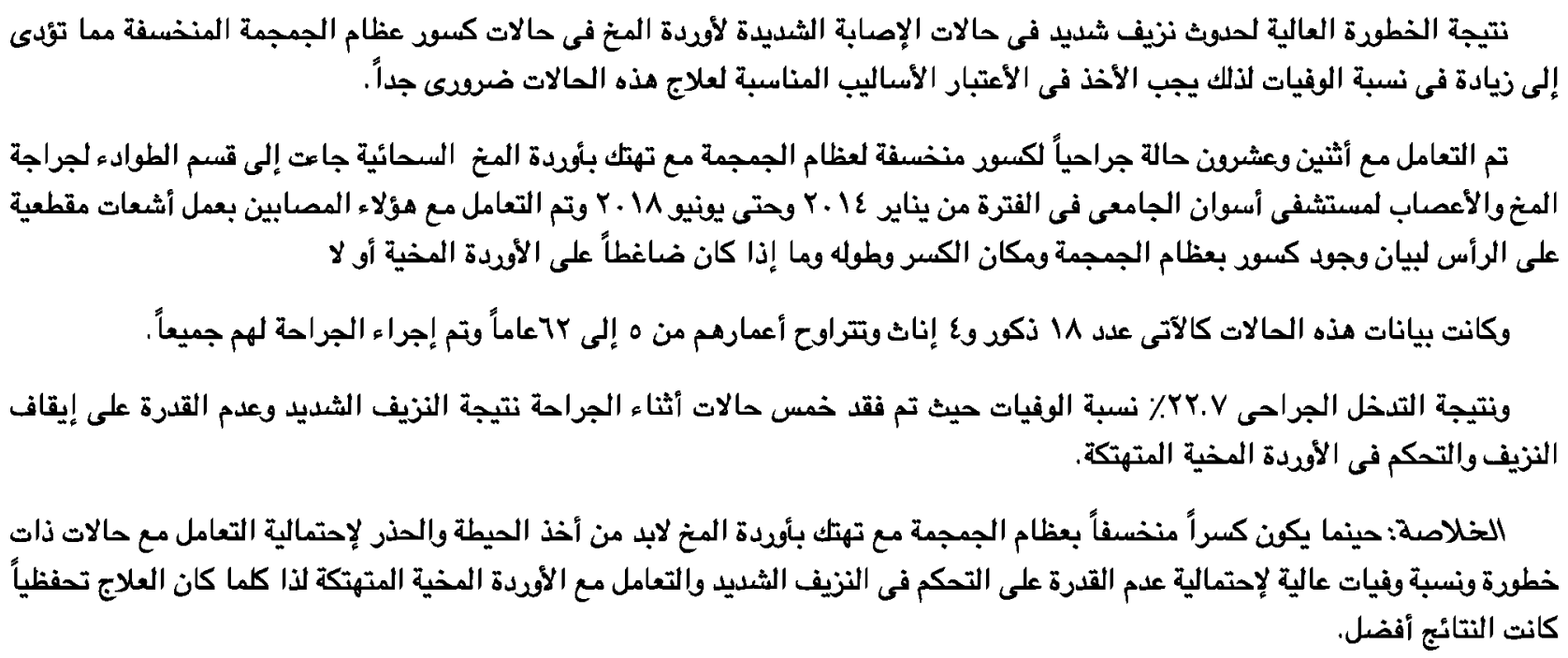

